\title{
Correspondence
}

\section{RCPSC CME timer}

To the Editor:

Canadian anesthesiologists should be aware that the Royal College of Physicians and Surgeons has mandated that all members of the College participate in "Maintenance of Certification". This requires them to undertake and record up to $400 \mathrm{hr}$ of CME every five years.

The rules concerning the appropriate types of CME and the documentation required for each type are complicated. I have created a Web site at www. ContinuousMedicalEducation.com to help specialist anesthesiologists meet the College's requirements. The site contains:

1. A CME Timer, which documents the time, date, and duration of Internet CME.

2. A Guide to Maintenance of Certification, which is clearer and more user-friendly than the College version.

3. Forms to document each type of CME, to ensure that all the details required by the College are noted.

4. Information about what "Personal Learning Projects (PLPs)" and "Practice Review" are, with many suggestions. An example PLP, "How can I use the Internet for CME?" is worked through in detail.

5. A Learning Needs Assessment Form, to help decide what areas need further study.

6. Journal Watch, a review of the latest major anesthesia journals.

7. Resources - annotated links to Medline searches, Internet searches, anesthesia Web sites and major journals.

8. QuickQuiz - a five-minute test on various aspects of medical care, marked instantly, with a report sent to the user by email.

9. A Discussion area, to allow comments and col laboration. A sophisticated program is used, which allows grouping of messages devoted to the same subject, and includes the option for users to be notified when there is a response to their message.

10. Contact, support and sponsorship information.

John Oyston MB FFARCS FRCPC

Toronto, Ontario
Early use of curare in England. Correspondence between H. Griffith and R.R. Macintosh

To the Editor:

Griffith and Johnson introduced curare with their paper "The use of curare in general anesthesia". Previously unpublished correspondence between Harold Griffith and Robert Macintosh, has allowed us to establish the early use of curare in England before it was introduced into the English market,

Robert Macintosh was in touch with Griffith as a result of their mutual involvement in Air Force medical matters during the Second World War. ${ }^{2}$ Macintosh heard about curare in a letter from Griffith on 17th June 1942:

"I enclose a report which we have just completed on Curare and which will appear in the July number of Anesthesiology. As you can see, we have been greatly pleased with its use and we feel that it has a definite place in anesthesia. I am sure the Squibb Company would be glad to let you have some for experimental use if you would like to try it out. Our surgeons are enthusiastic about it”. ${ }^{3}$

This provided Macintosh with early access to curare. In a film on artificial respiration from Macintosh's Department in 1943, the patient was paralysed with Curarine. ${ }^{2}$ Macintosh contributed to its more widespread use through articles and lectures. ${ }^{4,5}$ In a letter to Griffith, in 1945 he states: ${ }^{6}$

"On Friday 22nd (June), I gave a short paper on "Curare " to Service anaesthetists in the U.S.A. Hospitals. (...) I told them that I thought that your introduction of this substance promises to be one of the really big advances in anaesthesia."

The relationship between Griffith and Macintosh, encouraged the early introduction of curare in England.

M.C. Unzueta

C. Hervis

J.M. Villar Landeira

Barcelona, Spain

References

1 Griffith HR, Jonhson E. The use of curare in general anesthesia. Anesthesiology 1942; 3: 418-20. 